\title{
JS-K promotes apoptosis by inducing ROS production in human prostate cancer cells
}

\author{
MINGNING QIU*, LIEQIAN CHEN*, GUOBIN TAN, LONGZHI KE, SAI ZHANG, HEGE CHEN and JIANJUN LIU \\ Laboratory of Urology, Guangdong Medical University, Zhanjiang, Guangdong 524001, P.R. China
}

Received June 16, 2015; Accepted October 28, 2016

DOI: $10.3892 / 01.2016 .5535$

\begin{abstract}
Reactive oxygen species (ROS) are chemical species that alter redox status, and are responsible for inducing carcinogenesis. The purpose of the present study was to assess the effects of the glutathione $S$ transferase-activated nitric oxide donor prodrug, JS-K, on ROS accumulation and on proliferation and apoptosis in human prostate cancer cells. Cell proliferation and apoptosis, ROS accumulation and the activation of the mitochondrial signaling pathway were measured. The results demonstrated that JS-K may inhibit prostate cancer cell growth in a dose- and time-dependent manner, and induce ROS accumulation and apoptosis in a dose-dependent manner. With increasing concentrations of JS-K, expression of pro-apoptotic proteins increased, but Bcl-2 expression decreased. Additionally, the antioxidant $\mathrm{N}$-acetylcysteine reversed JS-K-induced cell apoptosis; conversely, the pro-oxidant glutathione disulfide exacerbated JS-K-induced apoptosis. In conclusion, the data suggest that JS-K induces prostate cancer cell apoptosis by increasing ROS levels.
\end{abstract}

\section{Introduction}

JS-K $\left(\mathrm{C}_{13} \mathrm{H}_{16} \mathrm{~N}_{6} \mathrm{O}_{8}\right.$; CAS No., 205432-12-8) is a glutathione $\mathrm{S}$ transferase (GST)-activated nitric oxide (NO) donor prodrug and is able to generate high intracellular levels of NO (1). JS-K uniquely requires GST for its optimal activity; it may use GST overexpression to generate high intracellular concentrations of cytotoxic NO specifically within tumor cells, causing an anticancer effect (2). Thus, it has selective antitumor roles against human tumors in vivo and in vitro,

Correspondence to: Dr Hege Chen or Professor Jianjun Liu, Laboratory of Urology, Guangdong Medical University, 57 Renmin Road, Zhanjiang, Guangdong 524001, P.R. China

E-mail: hegechen@163.com

E-mail: jianjunliulab@163.com

\section{${ }^{*}$ Contributed equally}

Key words: apoptosis, reactive oxygen species, JS-K, nitric oxide, prostate cancer cells whereas it has no marked toxicity toward normal cells (2). NO regulates intercellular reactive oxygen species (ROS) levels by producing several reactive nitrogen species (RNS) (3). A previous study demonstrated that JS-K is highly effective in suppressing non-small-cell lung cancer cell proliferation by increasing basal levels of ROS (4). JS-K is also reported to have antitumor activity in prostate cancer cells, particularly in castration-resistant (androgen-independent) cells (5). However, the effects of ROS during JS-K-induced prostate cancer cell apoptosis have not been characterized. The purpose of the current study was to investigate the cytotoxic effects of JS-K on the proliferation and apoptosis of human prostate cancer cells, and to investigate a possible ROS-associated etiology. The present study revealed the essential role of ROS in JS-K-induced prostate cancer cell apoptosis.

\section{Materials and methods}

Reagents and cell culture. JS-K was purchased from Santa Cruz Biotechnology, Inc. (Dallas, TX, USA). N-acetylcysteine (NAC) and glutathione disulfide (GSSG) were purchased from Beyotime Institute of Biotechnology (Haimen, China). The human prostate cancer cell lines 22RV1, LNCap and PC-3 were purchased from Shanghai Institute of Biochemistry and Cell Biology (Shanghai, China); C4-2 cells were obtained from American Type Culture Collection (Manassas, VA, USA). All cell lines were cultured in RPMI-1640 medium (Gibco; Thermo Fisher Scientific, Inc., Waltham, MA, USA) supplemented with $10 \%$ (v/v) fetal bovine serum (Gibco), $100 \mathrm{U} / \mathrm{ml}$ penicillin and $100 \mathrm{U} / \mathrm{ml}$ streptomycin at $37^{\circ} \mathrm{C}$ in an atmosphere containing $5 \% \mathrm{CO}_{2}$ and humidified air.

Cell proliferation assay. Cell proliferation was measured with a Cell Counting kit-8 (CCK-8; Dojindo Molecular Technologies, Inc., Kumamoto, Japan) according to the manufacturer's instructions. Cells were seeded into 96-well plates (Corning Incorporated, Corning, NY, USA) at a density of $10^{4}$ cells/well and allowed to adhere for $24 \mathrm{~h}$. JS-K was prepared as a $5 \mathrm{mM}$ stock solution in DMSO. Cells were treated with increasing concentrations of JS-K for 12, 24 and $48 \mathrm{~h}$. The culture medium was removed and replaced with $100 \mu \mathrm{l}$ medium containing $10 \%$ (v/v) CCK-8 reagent, then incubated at $37^{\circ} \mathrm{C}$ for $2 \mathrm{~h}$. Absorbance was recorded at $450 \mathrm{~nm}$ in a 96-well plate reader (PerkinElmer, Waltham, MA, USA). 
Apoptosis analysis. Apoptosis assays were performed using a FITC Annexin V Apoptosis Detection kit I (BD Biosciences, Franklin Lakes, NJ, USA), according to the manufacturer's protocols.

Measurement of intracellular ROS. Accumulation of ROS was quantified by flow cytometry following use of a Reactive Oxygen Species Assay kit (Beyotime Institute of Biotechnology). Briefly, cells $\left(3 \times 10^{5}\right)$ were exposed to JS-K for $6 \mathrm{~h}$ at $37^{\circ} \mathrm{C}$, and were collected and resuspended with serum-free medium containing 2',7'-dichlorofluorescin (DCFH) diacetate reagent, following which cells were incubated at $37^{\circ} \mathrm{C}$ for $20 \mathrm{~min}$ in the dark. DCFH fluorescence intensity was measured by flow cytometry (FACSCalibur; BD Biosciences) with the excitation source at $488 \mathrm{~nm}$ and emission at $525 \mathrm{~nm}$.

RNS assay. Nitrite ion $\left(\mathrm{NO}_{2}^{-}\right)$presence was used to define RNS in the present study; RNS levels were therefore measured with a Nitrite Assay kit (Beyotime Institute of Biotechnology) according to the manufacturer's instructions.

Superoxide measurement. Superoxide level was measured with a Superoxide Assay kit (Beyotime Institute of Biotechnology) according to the manufacturer's instructions. Briefly, the cells were treated with JS-K for $6 \mathrm{~h}$ at $37^{\circ} \mathrm{C}$, then superoxide detection reagent was added into each well (200 $\mu \mathrm{l} /$ well) and cells were incubated at $37^{\circ} \mathrm{C}$ for $20 \mathrm{~min}$. The absorbance was recorded at $450 \mathrm{~nm}$ in a 96 -well plate reader (PerkinElmer, Inc.).

Glutathione (GSH) content assay. Prostate cancer cells were cultured in 6-well plates at a density of $3 \times 10^{5}$ cells/well and were treated with different concentrations of JS-K for $6 \mathrm{~h}$ at $37^{\circ} \mathrm{C}$. Following treatment, cells were lysed by two successive rounds of freezing and thawing. The supernatant was obtained by centrifuging at $10,000 \times \mathrm{g}$ for $10 \mathrm{~min}$, and glutathione and GSSG levels was quantified with a GSH and GSSG Assay kit (Beyotime Institute of Biotechnology) according to the manufacturer's instructions.

Measurement of mitochondrial membrane potential. Cells were seeded in 6-well plates at $3 \times 10^{5}$ cells/well and exposed to various concentrations of JS-K for $3 \mathrm{~h}$ at $37^{\circ} \mathrm{C}$. The JC-1 Mitochondrial membrane potential assay kit (Beyotime Institute of Biotechnology) was then used according to manufacturer's protocols.

ATP production measurement. ATP levels in prostate cancer cells, after treatment with JS-K for $6 \mathrm{~h}$, were measured using an ATP Assay kit (Beyotime Institute of Biotechnology) according to the manufacturer's instructions.

Western blot analysis. Prostate cancer cells were lysed with radioimmunoprecipitation assay buffer (Beyotime Institute of Biotechnology) supplemented with $1 \mathrm{mM}$ phenylmethylsulfonyl fluoride (Beyotime Institute of Biotechnology). Cell lysates (30 $\mu \mathrm{g}$ protein) were separated by sodium dodecyl sulfate polyacrylamide gel electrophoresis and then transferred to polyvinylidene fluoride membranes (EMD Millipore, Billerica, MA, USA). The membranes were incubated with antibodies against BAK (\#3814; dilution 1:1,000), Bax (\#2772; dilution 1:1,000), Bcl-2 (\#2876; dilution 1:1,000), caspase-9 (\#9502; dilution 1:1,000), poly ADP ribose polymerase (PARP; \#9542; dilution 1:1,000) (all Cell Signaling Technology, Inc., Danvers, MA, USA) and glyceraldehyde 3-phosphate dehydrogenase (GAPDH; \#ab37168; Abcam, Cambridge, UK; dilution 1:100,000) in diluent overnight $(16 \mathrm{~h})$ at $4^{\circ} \mathrm{C}$. The membranes were then probed with horseradish peroxidase-conjugated goat anti-rabbit immunoglobulin G secondary antibody (\#E030120; EarthOx Life Sciences, Millbrae, CA, USA; dilution 1:10,000) for $1 \mathrm{~h}$.

Statistical analysis. All assays were performed in triplicate. The results are presented as mean \pm standard deviation. Statistical analysis was carried out by using a one-way analysis of variance using SPSS v. 18.0 software (SPSS, Inc., Chicago, IL, USA). Differences were assessed by Fisher's Least Significant Difference test and $\mathrm{P}<0.05$ was considered to represent a statistically significant difference.

\section{Results}

$J S-K$ suppresses proliferation and induces apoptosis in prostate cancer cells. The CCK-8 assay was performed to investigate the inhibition of cell proliferation in prostate cancer cells treated with JS-K. Prostate cancer cell proliferation was significantly inhibited by JS-K in a dose- and time-dependent manner $(\mathrm{P}<0.01$; Fig. 1$)$. Flow cytometry was used to evaluate the apoptosis-inducing effect of JS-K in prostate cancer cells. Treatment with JS-K for $24 \mathrm{~h}$ increased the proportion of apoptotic prostate cancer cells in a dose-dependent manner (Fig. 2). The proportion of apoptotic cells were significantly higher in the JS-K-treated cells compared with the respective control group $(0 \mu \mathrm{M})$ in all of the prostate cancer cell lines $(\mathrm{P}<0.05)$. Furthermore, 22RV1 and C4-2 cells appeared markedly more sensitive to JS-K treatment than LNCap and PC-3 cells.

$J S-K$ increases ROS and RNS levels and decreases the GSH/GSSG ratio in prostate cancer cells. The total ROS, RNS and superoxide levels were examined in prostate cancer cells that were treated with different concentrations of JS-K for $6 \mathrm{~h}$. Significant increases in total ROS (Fig. 3A-a), RNS (Fig. 3A-b) and superoxide levels (Fig. 3A-c) were observed in prostate cancer cells treated with $5 \mu \mathrm{M} \mathrm{JS}-\mathrm{K}(\mathrm{P}<0.01)$ and, in a number of cases across the cell lines, those treated with 1 or $2 \mu \mathrm{M}$ JS-K $(\mathrm{P}<0.01$ or $<0.05$ in all metrics and cell lines except ROS levels in LNCap and PC-3). Intracellular levels of GSH and GSSG were also assessed to determine the effects of JS-K on oxidative stress, revealing that the GSH/GSSG ratio was significantly decreased (Fig. $3 \mathrm{~A}-\mathrm{d}$; $\mathrm{P}<0.01$ in all cell lines except PC-3 cells exposed to $1 \mu \mathrm{M}$ JS-K). These data suggest that JS-K may induce an imbalance of the redox state and may promote mitochondrial dysfunction and mitochondria-mediated apoptosis.

$J S-K$ reduces mitochondrial membrane potential and ATP levels in prostate cancer cells. To investigate the mitochondrial energy production, the mitochondrial membrane potential and intracellular production of ATP in JS-K-treated 

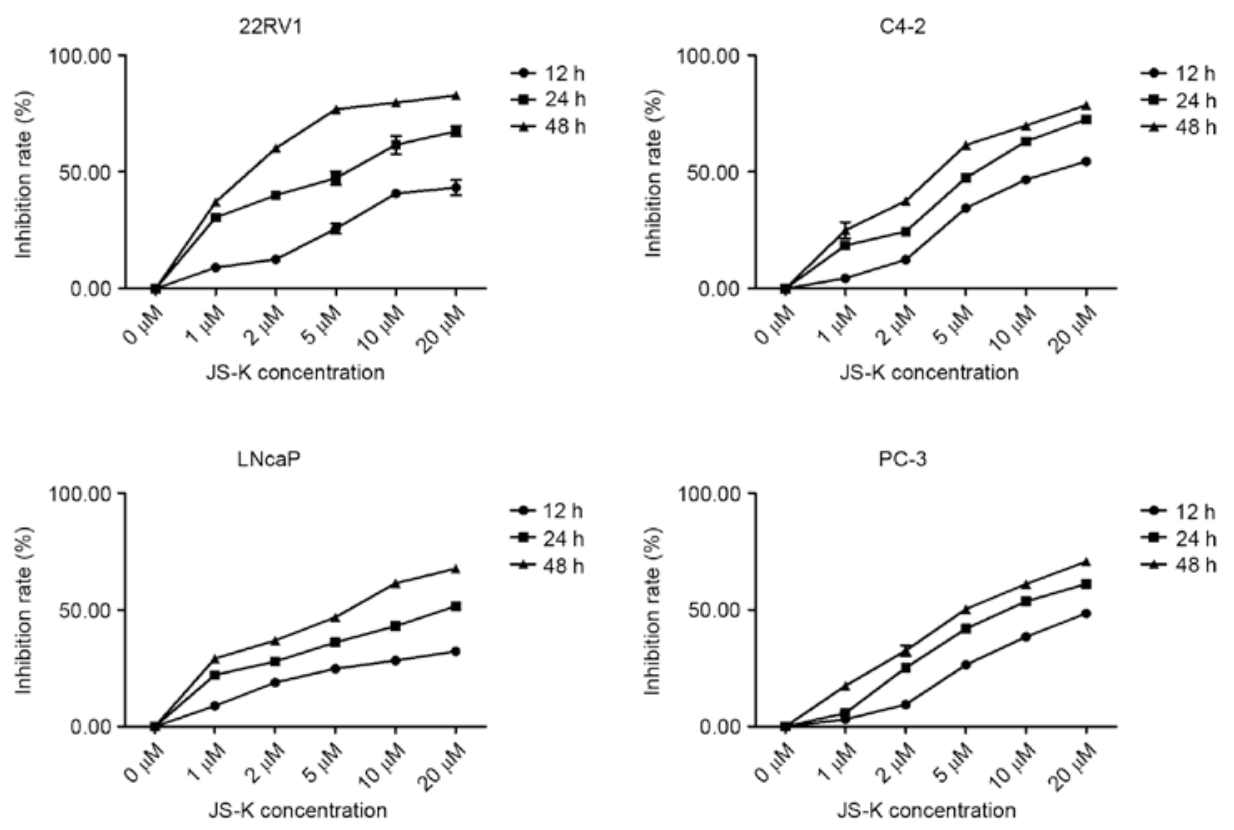

Figure 1. Inhibition of cell proliferation of prostate cancer cells following JS-K treatment. Cells were exposed to various concentrations of JS-K (1,2, 5, 10 or $20 \mu \mathrm{M}$ ) for 12,24 or $48 \mathrm{~h}$, and the inhibition rate of cells without JS-K treatment was defined as $0 \%$. Each sample was duplicated, and the figures present three independent assays $(n=6)$. Results are presented as mean \pm standard deviation.

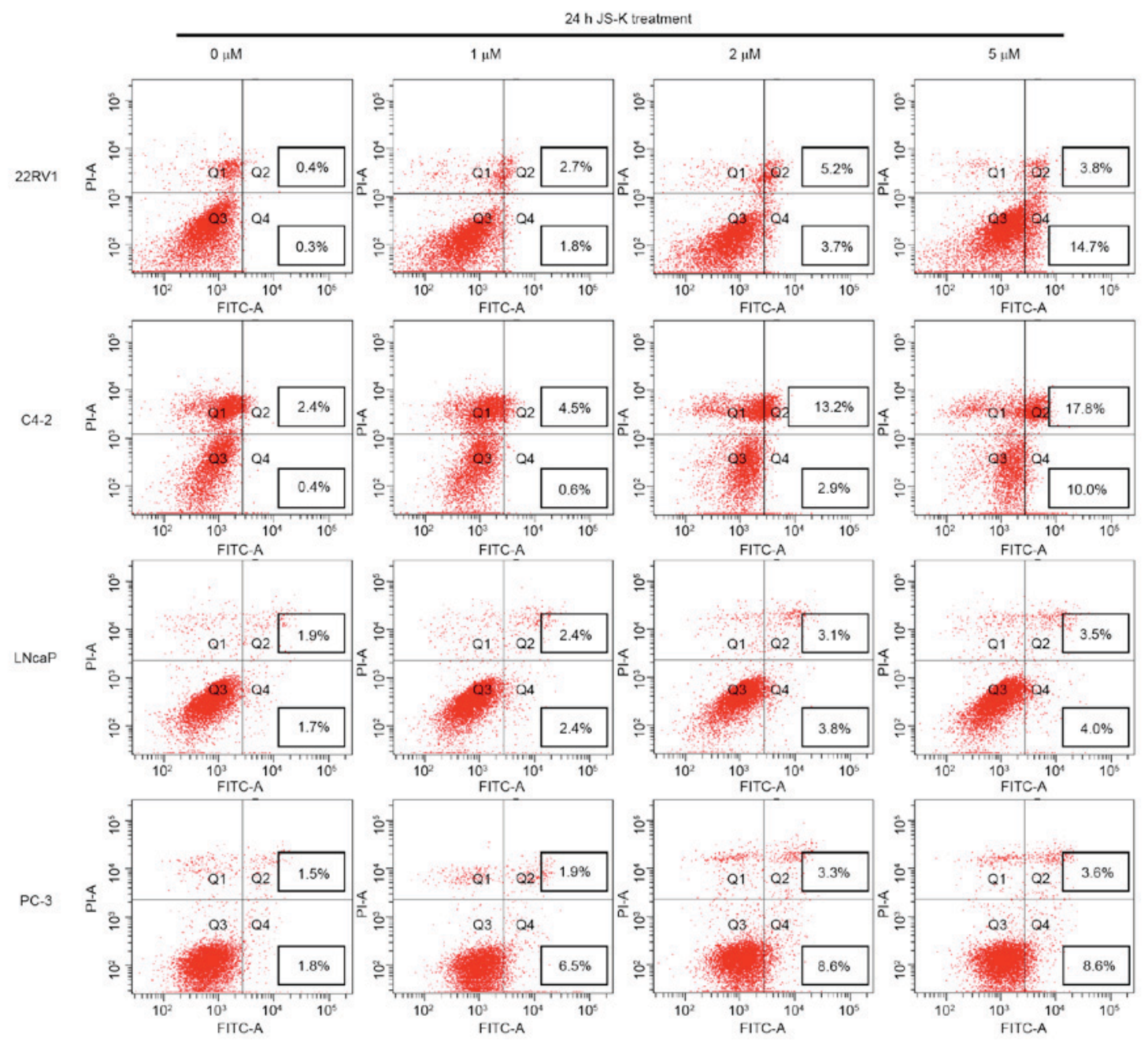

Figure 2. JS-K-induced apoptosis in prostate cancer cells, analyzed by flow cytometry with the Annexin V staining method. Untreated cells were analyzed as the control group. PI, propidium iodide; FITC, fluorescein isothiocyanate. 
A$$
\text { a }
$$
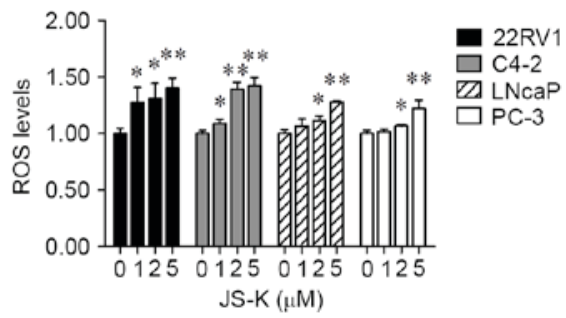

c

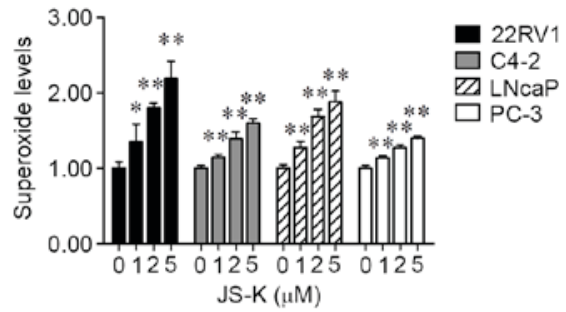

B
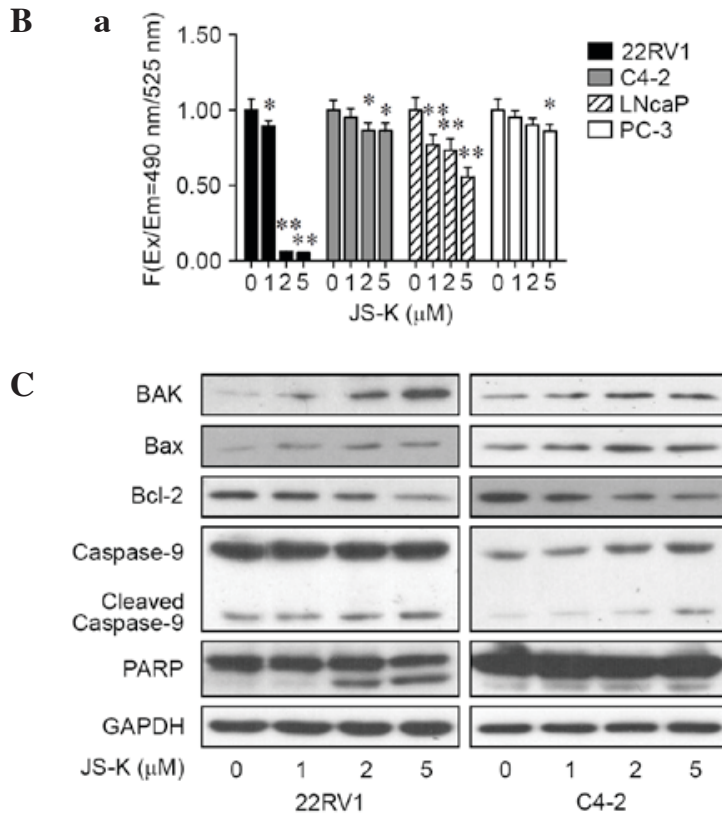

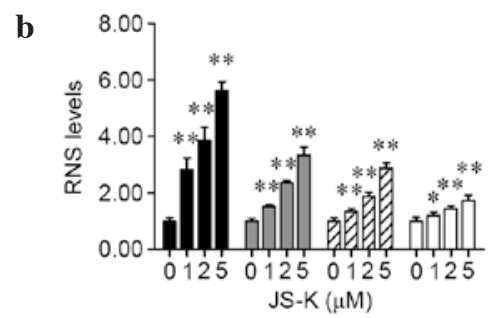

d

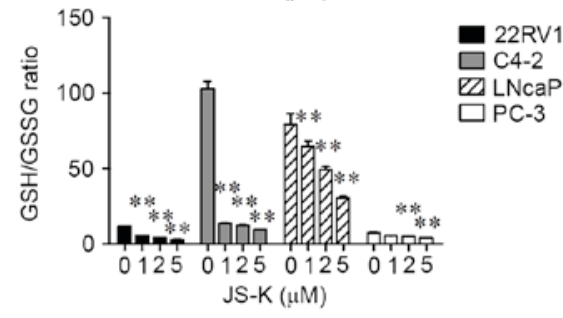

b
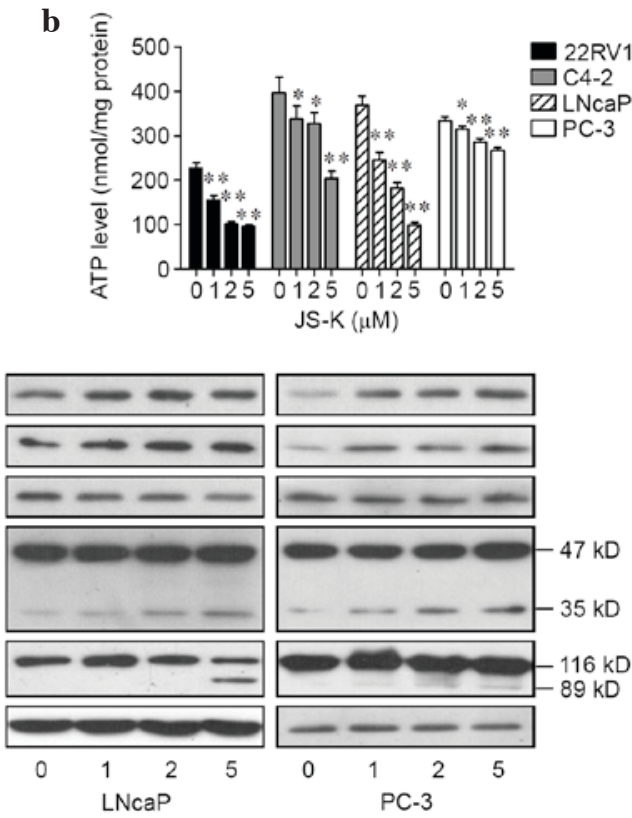

Figure 3. Effect of JS-K on ROS, RNS, GSH/GSSG ratio, mitochondrial membrane potential, ATP production and apoptotic-associated proteins in prostate cancer cells. (A) Prostate cancer cells were treated with JS-K $(0,1,2$ or $5 \mu \mathrm{M})$ for $6 \mathrm{~h}$ prior to assessment of the intracellular levels of (a) total ROS, (b) RNS and (c) superoxide, and (d) the GSH/GSSG ratio. (B) Following $6 \mathrm{~h} \mathrm{JS-K}$ treatment, (a) the mitochondrial membrane potential and (b) ATP production were measured. (C) The levels of BAK, Bax, Bcl-2, caspase-9 and PARP proteins were detected by western blotting following JS-K $(0,1,2$ or $5 \mu \mathrm{M})$ treatment for $24 \mathrm{~h}$. Results are presented as mean \pm standard deviation for at least three independent assays. " $\mathrm{P}<0.05$ and ${ }^{* *} \mathrm{P}<0.01$ vs. the corresponding untreated group $(0 \mu \mathrm{M})$. ROS, reactive oxygen species; RNS, reactive nitrogen species; GSH, glutathione; GSSG, glutathione disulfide; ATP, adenosine triphosphate; PARP, poly ADP ribose polymerase; GAPDH, glyceraldehyde 3-phosphate dehydrogenase.

prostate cancer cells were detected. Cells were treated with various concentrations of JS-K for $6 \mathrm{~h}$, and data indicated that the mitochondrial membrane potential (Fig. 3B-a) and intracellular levels of ATP (Fig. 3B-b) significantly decreased in a dose-dependent manner $(\mathrm{P}<0.01$ or $<0.05$ in all cell lines at $5 \mu \mathrm{M}$ JS-K treatment in all cell lines, and at 1 and $2 \mu \mathrm{M}$ in a number of cell lines).

Effects of JS-K on production of apoptotic proteins in prostate cancer cells. The expression of apoptotic proteins in mitochondria-mediated apoptosis was examined in prostate cancer cells following treatment with various concentrations of JS-K for $24 \mathrm{~h}$, revealing increased levels of caspase- 9 and cleaved PARP in JS-K-treated cells compared with the untreated, negative controls (Fig. 3C). The pro-apoptotic proteins BAK and Bax were upregulated in these cells, whereas Bcl-2 was downregulated in a dose-dependent manner (Fig. 3C).

Effects of NAC and GSSG on JS-K-induced cell growth suppression and apoptosis. To illustrate the role of ROS in JS-K-induced cell growth suppression and apoptosis, prostate cancer cells were treated with $5 \mu \mathrm{M}$ JS-K in the presence or absence of the antioxidant NAC $(100 \mu \mathrm{M})$ or pro-oxidant GSSG $(5 \mu \mathrm{M})$ for $24 \mathrm{~h}$. As shown in Fig. 4, the data indicated that NAC reversed JS-K-induced cell growth suppression and apoptosis and recovered levels of ROS $(\mathrm{P}<0.05)$, while GSSG significantly exacerbated JS-K-induced cell growth inhibition and apoptosis and increased the production of ROS $(\mathrm{P}<0.05)$. There were no significant differences between the cell survival rates and apoptosis rates of the cells treated with NAC or GSSG alone and the control group. 
A

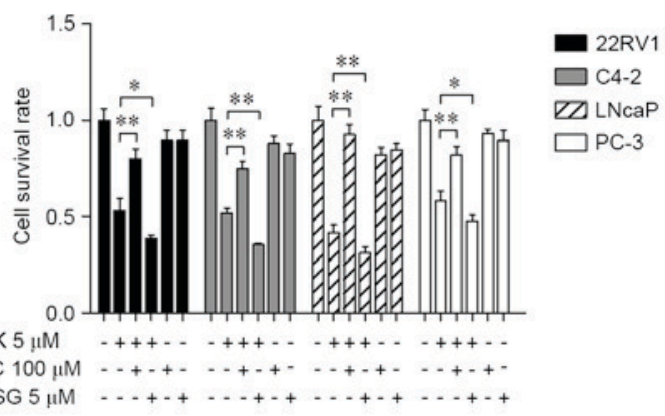

B

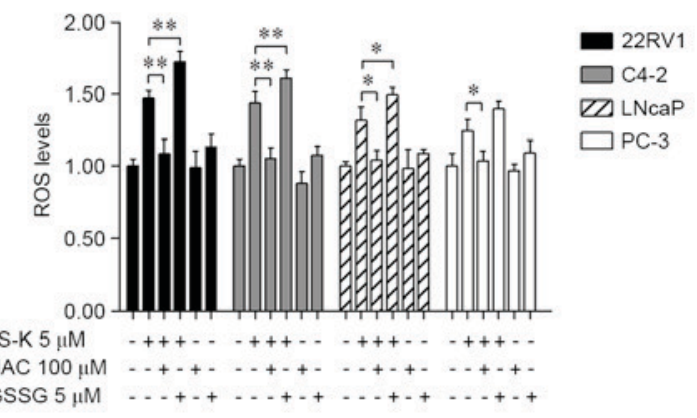

C
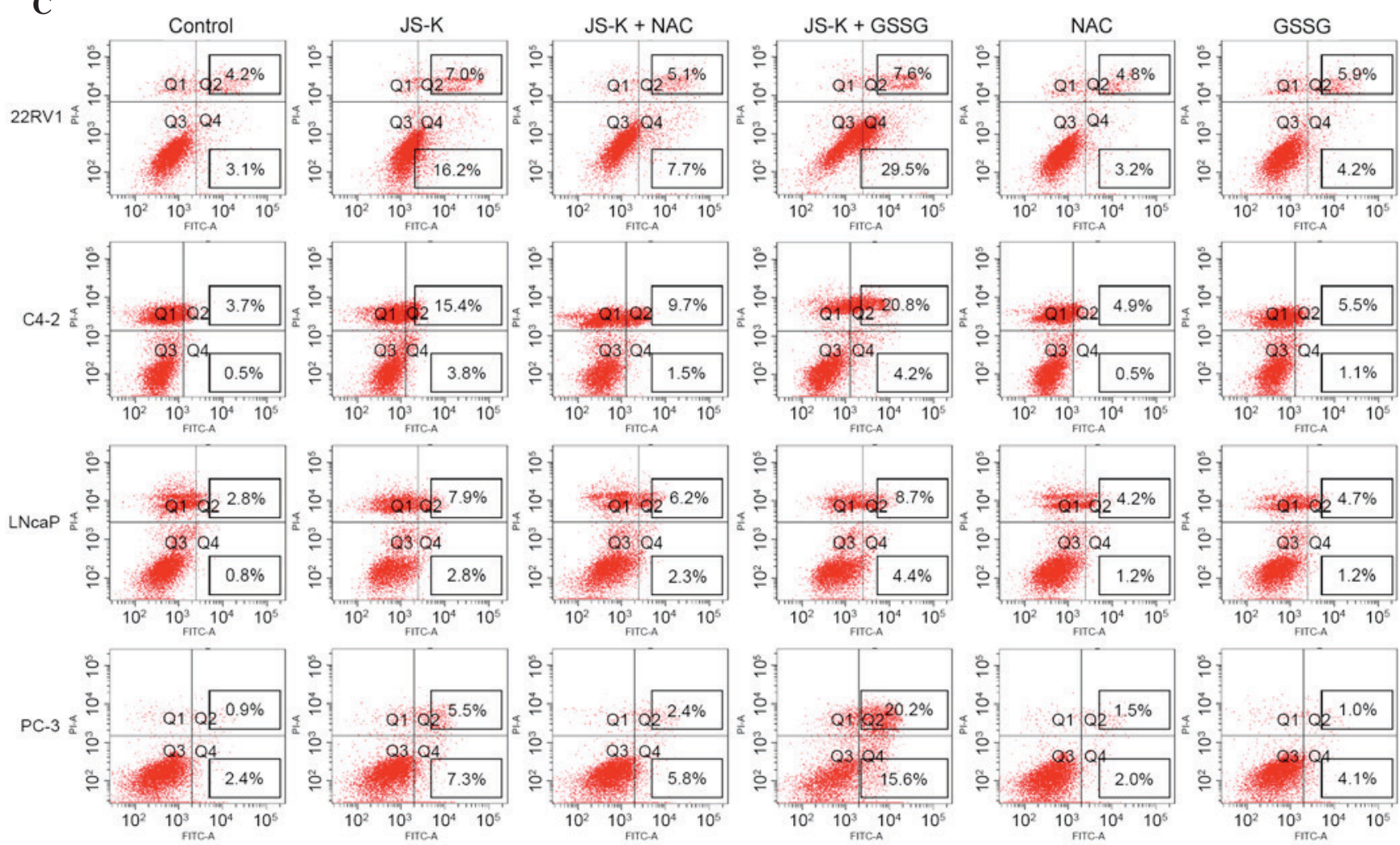

Figure 4. Effects of NAC and GSSG on JS-K-induced cell growth suppression and apoptosis in prostate cancer cells. (A) Cells were cultured with $100 \mu \mathrm{M}$ NAC or $5 \mu \mathrm{M}$ GSSG for $24 \mathrm{~h}$, and then treated with or without $5 \mu \mathrm{M} \mathrm{JS}-\mathrm{K}$ for $24 \mathrm{~h}$. Cell survival was measured by cell counting kit-8 assay. (B) Cells were pretreated with $100 \mu \mathrm{M}$ NAC or $5 \mu \mathrm{M}$ GSSG for $24 \mathrm{~h}$, treated with or without $5 \mu \mathrm{M}$ JS-K for $6 \mathrm{~h}$ and ROS production was measured. (C) Cell apoptosis was analyzed in the indicated groups. The mean \pm standard deviation is reported for at least three independent experiments. $\mathrm{P}<0.05$; ${ }^{* *} \mathrm{P}<0.01$ vs. specified group. NAC, N-acetylcysteine; GSSG, glutathione disulfide; ROS, reactive oxygen species.

\section{Discussion}

As a nitric oxide-releasing prodrug, JS-K appears to have a selective cytotoxic effect against various types of human cancers. The cytotoxic effects of JS-K have mainly been attributed to its capability of releasing high levels of NO upon conjugation with glutathione by GST enzymes (1). JS-K was previously reported to inhibit cell growth, androgen receptor signaling and Wnt signaling in prostate cancer cells (5). JS-K-released NO is a signaling molecule that increases intracellular ROS levels (4). Thus, JS-K-released NO is hypothesized to promote prostate cancer cell apoptosis via a ROS activation mechanism. In the present study, JS-K had a cytotoxic effect against prostate cancer cells, increasing ROS production. The cytotoxic effect of JS-K was reversed by NAC and was exacerbated by GSSG.
ROS are critical signaling molecules for cell proliferation and apoptosis (6). ROS also activate intracellular signal transduction pathways that regulate multiple cellular processes including inflammation, cell cycle progression, apoptosis, migration and invasion in cancer (7). JS-K-released NO was previously reported to generate markedly increased intracellular levels of ROS (4). Excessive ROS generation is reported to result in an inhibition of epithelial-mesenchymal transition and growth arrest in prostate cancer cells (8). In the present study, ROS/RNS levels significantly increased in prostate cancer cells treated with JS-K compared with untreated cells; furthermore, significantly increased cell inhibition and apoptosis rates were observed. Alterations to ROS, RNS and superoxide levels, cell inhibition rate and apoptosis rate were previously detected in castration-resistant cells, suggesting a marked sensitivity to JS-K, in agreement with the present 
results (5). In addition, administration of the antioxidant NAC reversed the JS-K-mediated anticancer effect, and the prooxidant GSSG exacerbated the anticancer effect of JS-K, suggesting that elevation of ROS may be a mechanism by which JS-K implements an anticancer role in prostate cancer cells.

GSH is an important antioxidant involved in mitochondrial dysfunction and cell apoptosis, and depletion of GSH may result in redox imbalance (9). The current study demonstrated that JS-K significantly reduced GSH production and increased GSSG production, which resulted in a decrease in the GSH/GSSG ratio. Furthermore, ATP is recognized as a direct energy source for cellular metabolism, and ATP production may be regulated by loss of mitochondrial membrane potential during apoptosis (4). The current data indicated that JS-K significantly reduces mitochondrial membrane potential and ATP levels in a dose-dependent manner. Furthermore, an upregulated level of cleaved caspase-9 was observed, which is an important member of the caspase family $(10,11)$. PARP is a substrate of caspase-9 that is involved in DNA repair in response to environmental stress, and cleaved PARP is recognized as a marker of cells undergoing apoptosis $(12,13)$. Bcl-2, Bax and BAK are key components in mitochondrial stress-induced cellular apoptosis, and an appropriate balance of Bcl-2 and Bax is crucial for cell survival $(14,15)$. In the present study, JS-K increased expression levels of cleaved caspase-9, cleaved PARP, Bax and BAK proteins in prostate cancer cells, whilst reducing $\mathrm{Bcl}-2$ protein expression, suggesting that JS-K-induced accumulation of ROS may promote mitochondria-mediated apoptosis in prostate cancer cells.

In summary, the current study investigated the effects of JS-K on human prostate cancer cells, confirming that JS-K significantly suppresses cell proliferation and induces apoptosis in human prostate cancer cells, correlating with a high accumulation of ROS. ROS production is therefore hypothesized to be an essential step in JS-K-induced mitochondria-dependent cellular apoptosis. Taken together, the present data suggested that JS-K induces apoptosis through an ROS-associated pathway in human prostate cancer cells.

\section{Acknowledgements}

The present work was supported by the following grants: The Scientific Research Fund of Guangdong Medical College, China (grant no. M2014019) and The National Natural Science Fund of China (grant no. 81272833).

\section{References}

1. Shami PJ, Saavedra JE, Wang LY, Bonifant CL, Diwan BA, Singh SV, Gu Y, Fox SD, Buzard GS, Citro ML, et al: JS-K, a glutathione/glutathione S-transferase-activated nitric oxide donor of the diazeniumdiolate class with potent antineoplastic activity. Mol Cancer Ther 2: 409-417, 2003.

2. Kiziltepe T, Hideshima T, Ishitsuka K, Ocio EM, Raje N, Catley L, Li CQ, Trudel LJ, Yasui H, Vallet S, et al: JS-K, a GST-activated nitric oxide generator, induces DNA double-strand breaks, activates DNA damage response pathways, and induces apoptosis in vitro and in vivo in human multiple myeloma cells. Blood 110: 709-718, 2007.

3. Hsieh HJ, Liu CA, Huang B, Tseng AH and Wang DL: Shear-induced endothelial mechanotransduction: The interplay between reactive oxygen species (ROS) and nitric oxide (NO) and the pathophysiological implications. J Biomed Sci 21: 3, 2014.

4. Maciag AE, Chakrapani H, Saavedra JE, Morris NL, Holland RJ, Kosak KM, Shami PJ, Anderson LM and Keefer LK: The nitric oxide prodrug JS-K is effective against non-small-cell lung cancer cells in vitro and in vivo: Involvement of reactive oxygen species. J Pharmacol Exp Ther 336: 313-320, 2011.

5. Laschak M, Spindler KD, Schrader AJ, Hessenauer A, Streicher W, Schrader M and Cronauer MV: JS-K, a glutathione/glutathione S-transferase-activated nitric oxide releasing prodrug inhibits androgen receptor and WNT-signaling in prostate cancer cells. BMC Cancer 12: 130, 2012.

6. Ray PD, Huang BW and Tsuji Y: Reactive oxygen species (ROS) homeostasis and redox regulation in cellular signaling. Cell Signal 24: 981-990, 2012.

7. Wu WS: The signaling mechanism of ROS in tumor progression. Cancer Metastasis Rev 25: 695-705, 2006.

8. Das TP, Suman S and Damodaran C: Induction of reactive oxygen species generation inhibits epithelial-mesenchymal transition and promotes growth arrest in prostate cancer cells. Mol Carcinog 53: 537-547, 2014.

9. Nie F, Zhang X, Qi Q, Yang L, Yang Y, Liu W, Lu N, Wu Z, You Q and Guo Q: Reactive oxygen species accumulation contributes to gambogic acid-induced apoptosis in human hepatoma SMMC-7721 cells. Toxicology 260: 60-67, 2009.

10. Allan LA and Clarke PR: Apoptosis and autophagy: Regulation of caspase-9 by phosphorylation. FEBS J 276: 6063-6073, 2009.

11. Nicholson DW and Thornberry NA: Caspases: Killer proteases. Trends Biochem Sci 22: 299-306, 1997.

12. Satoh MS and Lindahl T: Role of poly (ADP-ribose) formation in DNA repair. Nature 356: 356-358, 1992.

13. Oliver FJ, Menissier-de Murcia J and de Murcia G: Poly(ADP-ribose) polymerase in the cellular response to DNA damage, apoptosis, and disease. Am J Hum Genet 64: 1282-1288, 1999.

14. Pöhland T, Wagner S, Mahyar-Roemer M and Roemer K: Bax and Bak are the critical complementary effectors of colorectal cancer cell apoptosis by chemopreventive resveratrol. Anticancer Drugs 17: 471-478, 2006.

15. Tasyriq M, Najmuldeen IA, In LL, Mohamad K, Awang K and Hasima N: $7 \alpha$-Hydroxy- $\beta$-Sitosterol from chisocheton tomentosus induces apoptosis via dysregulation of cellular $\mathrm{Bax} / \mathrm{Bcl}-2$ ratio and cell cycle arrest by downregulating ERK1/2 activation. Evid Based Complement Alternat Med 2012: 765316, 2012. 